\title{
Combining a Solution-Phase Derived Library with In-Situ Cellular Bioassay: Prompt Screening of Amide-Forming Minilibraries Using MTT Assay
}

\author{
Li-Wu Chinang, ${ }^{a}$ Kai Pei, ${ }^{a}$ Shao-Wei Chen, ${ }^{a}$ Ho-Lien Huang,,${ }^{a}$ Kun-Ju Lin, ${ }^{b}$ Tzu-Chen Yen,,${ }^{b}$ and \\ Chung-Shan $\mathrm{YU}^{*, a, c}$
}

${ }^{a}$ Department of Biomedical Engineering and Environmental Sciences, National Tsing-Hua University; ${ }^{c}$ Institute of Nuclear Engineering and Science, National Tsing-Hua University; Hsinchu 30043, Taiwan: and ${ }^{b}$ Department of Nuclear Medicine, Chang-Gung Memorial Hospital; Taoyuan 33305, Taiwan.

Received February 22, 2009; accepted April 3, 2009; published online April 7, 2009

We constructed a minilibrary using a solution-phase synthesis through coupling of three core amino compounds $\left(5^{\prime}\right.$-amino-5' -deoxy uridine, 5' -amino-2', $5^{\prime}$-di-deoxy arabinosyl uridine, and butan-1-amine) with 30 carboxylic acids via amide bond formation. The simplified structural core compound butan-1-amine was selectively coupled with 9 carboxylic acids as control. 3-(4,5-Dimethyl-2-thiazolyl)-2,5-diphenyl-2H-tetrazolium bromide assay of the crude mixtures showed that analogues derived from fenbufen, butylfenbufen C15; ethacrynic acid, butyl ethacrynic amide C18; and sphingosines, Sph-1, Sph-2 and U27 had an increased cytotoxicity against MCF-7 cells as well as A549 cells. Structural elucidation with molecular docking suggested that cytotoxicity of these compounds is mainly due to the inhibition of enzymes regulating cellular apoptosis.

Key words amide; assay; solution phase; in situ; library; molecular docking

There has been growing interest in a method combining a solution-phase derived library with an in-situ bioassay on microtiter plate. ${ }^{1)}$ Construction of the library is initiated through a core compound, either as a lead of natural product or a transition-state analog from mechanistic considerations, followed by coupling with various carboxylic acids as building blocks. The libraries were constructed on a microtiter plate or a set of centrifuge tubes. In each well or tube, the products obtained were screened for their binding affinity for the enzyme of interest. The bioactivity derived from the mixture, in general, is consistent with that of the purified product. Indeed, a number of potential substrates for numerous enzymes including sulfotransferase, ${ }^{2)}$ fucosidase, ${ }^{3)}$ fucosyltransferase, ${ }^{4)}$ protease, ${ }^{5)}$ and protease dimerization, have been discovered by this approach. ${ }^{6}$ Since this method is mainly focused on enzymatic assays, a further application in cellular assays may be of importance. In this article, we sought to couple the amide-forming libraries with a cell-line based assay. In addition, we elucidated the mechanisms related to bioactivity of potential amides through molecular docking.

As part of our ongoing research, we are focusing on the development of nucleoside analogs to be used as prodrugs to target herpes simplex virus thymidine kinase gene. ${ }^{7-9)}$ Thus, $5^{\prime}$-amino-5'-deoxy analogues of pyrimidine nucleosides set as a core compound. To clarify whether the bioactivity is mainly associated with the core 5 '-amino nucleoside compounds, a structurally simplified butan-1-amine was used as control for comparison purposes. In addition to the commercially available butan-1-amine, the preparation of these nucleoside analogs has been reported. ${ }^{10)}$ In this study, carboxylic acid moieties were structurally classified in four types as follows: mono-aromatic rings $(\mathbf{1}-\mathbf{1 5})$, di-aromatic rings $(\mathbf{1 6}-\mathbf{1 8})$, fused rings $(\mathbf{1 9}, \mathbf{2 0})$, and aliphatic groups containing heteroatoms such as phosphor and aza acids $\mathbf{2 1 -}$ 30 (Table 1).

The coupling product in each well was diluted before transfering to the plate. Thus the appropriate working con- centration could be determined since the cellular survival ratio of most compounds acting as negative control is greater than $80 \%$. The method is illustrated in Fig. 2.

As shown by crude assay results (Figs. $3 a-c)$, the cellular survival ratio for the majority of the products was over $60 \%$, suggesting the absence of cytotoxicity. On the other hand, the coupling products U27, A15, C15, and $\mathbf{C 1 8}$ exhibited biological activity. These potential compounds were further prepared and purified on flash chromatography to be submitted for a "clean" analysis. In contrast, we disregarded the evaluation of U15 due to the higher activity of its 2 '-epimer $\mathbf{A 1 5}$ against both A549 and MCF7 cell lines.

Unexpectedly, a subtle cytotoxicity of U27 was evident (Fig. 3b and supporting information: S16, S17). As a control, a referential core compound: butan-1-amine was coupled with the corresponding acid moieties to provide C27 (Fig. 3b). Since U27 shares structural similarities to sphingosine, the sphingosine analogs Sph-1 and Sph-2 (carbon length of 13 and 18 , respectively), were prepared for comparison pur-
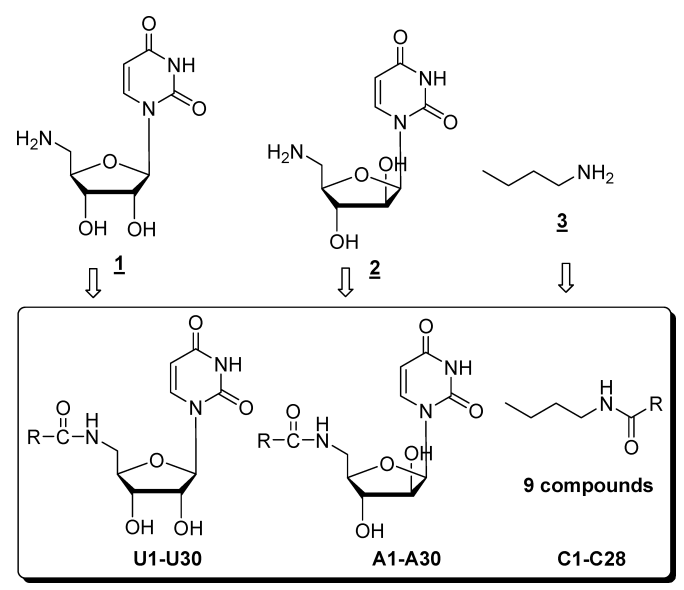

Fig. 1. Libraries Constructed through a Coupling of Three Core Amines with Carboxylic Acids 
Table 1. Carboxylic Acids as Building Blocks for Amide Bond Formation

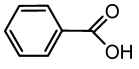

D1<smiles>CNc1ccc(C(=O)O)cc1</smiles>

D7<smiles>COc1cc(/C=C/C(=O)O)ccc1O</smiles>

D13<smiles>O=C(O)CCc1c[nH]c2ccccc12</smiles>

D19

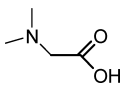

D25

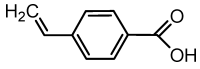

D2

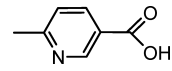

D8

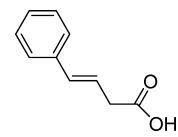

D14<smiles>CCn1cc(C(=O)O)c(=O)c2cnc(N3CCNCC3)nc21</smiles>

D20

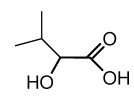

D26

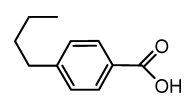

D3

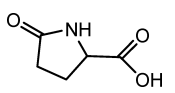

D9<smiles>CCC1CCC1C(=O)c1ccc(OCC(=O)O)c(Cl)c1Cl</smiles>

D15

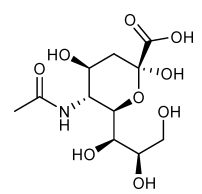

D21

$\mathrm{H}_{3} \mathrm{C}-\left(\mathrm{H}_{2} \mathrm{C}\right)_{9} \underset{\mathrm{OH}}{\mathrm{O}}$

D27

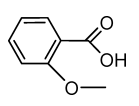

D4

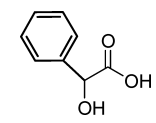

D10

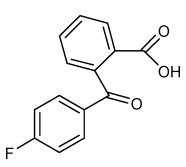

D16<smiles>O=C(O)C(Br)Br</smiles>

D22<smiles>CCCCC(=O)O</smiles>

D28

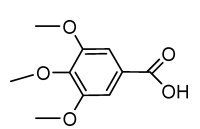

D5<smiles>CC(C)Cc1ccc(C(C)C(=O)O)cc1</smiles>

D11<smiles>O=C(O)c1cc(-c2ccc(F)c(F)c2)ccc1O</smiles>

D17<smiles>O=C(O)CP(=O)(O)O</smiles>

D23<smiles>CCCCCCC(Br)C(=O)O</smiles>

D29<smiles>Cc1ccc(C(=O)O)c(O)c1</smiles>

D6<smiles>Cc1ccc(C)c(OCCCC(C)(C)C(=O)O)c1</smiles>

D12

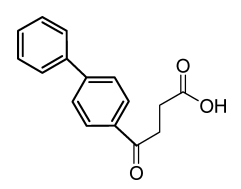

D18<smiles>CCNC(=O)/C=C\C(=O)O</smiles>

D24

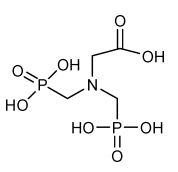

D30

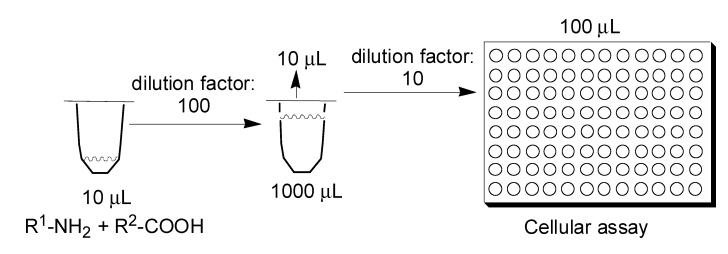

Fig. 2. Flowchart of the Dilution Process

poses (Fig. 4). While the bioactivity is mainly due to both the lipid part and the hydrophilic head, the hydrophilic moieties of sphingosine are more effective in inducing cytotoxicity. The hydrophilic moieties of sphingosine are capable to induce specific proapoptotic signals that may account for cytotoxicity. ${ }^{11-14)}$

In spite of the few data available on the membrane receptor and X-ray diffraction data, an attempt to clarify the probable binding mechanisms through molecular docking was performed. The START, known as a domain of steroidogenic acute regulatory protein-related lipid transfer (StARD10), has been reported to be overexpressed in breast cancer. ${ }^{15)}$ In addition, the START domain of ceramide transport (CERT) protein is known for its transferring ability of natural Derythro ceramides, mainly used for transporting from ER to Golgi apparatus. ${ }^{16)}$ The two START domains have similar characteristics and consist of 210 and 250 amino acids, respectively. The cavity of CERT START domain comprises a line of hydrophobic and polar charged heads. According to the crystal structure of the complex formed by CERT domain of $2 \mathrm{e} 3 \mathrm{n}$ with ceramides having acyl groups of various lengths, the hydrogen bond formed by the hydrophilic head of the substrate within the deep active site plays a critical role for the biological activity. ${ }^{16)}$ Notably, the $\mathrm{OH}$ group at $\mathrm{C}$ 1 forming a hydrogen bond with the guanidine group of arginine-442 is crucial. Our docking results (Figs. 5a-c) suggested a similar interaction formed among numerous amino acid residues including hydrophilic and hydrophobic contacts. Interestingly, the 4-OH group forms a hydrogen bond to $\mathrm{OH}$ of tyrosine-576 closing to the tyrosine-553, which is responsible for the hydrogen bond to the amide group of nat-

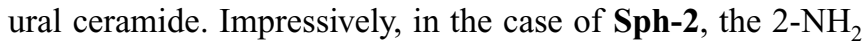
and 4-OH groups form hydrogen bonds to glutamine-467 and tyrosine-553, respectively (Fig. 5c). Similarly, although the $3^{\prime}-\mathrm{OH}$ group of $\mathbf{U} 27$ forms a hydrogen bond to the $\mathrm{OH}$ of threonine-448, the cavity is still able to accommodate the pyrimidine base ring (Fig. 5d). Our results suggest that the START domain is the site potentially responsible for mediating apoptosis through these lipid analogs.

During the crude assay of C-series compounds, an unexpected bioactivity of $\mathbf{C 1 8}$ against both A549 and MCF7 was evident (Fig. 16 and 17 in S.I., Table 2). Acid moieties D18 also known as fenbufen is a member of the non-steroid antiinflammatory drugs (NSAIDs). As an inhibitor targeting cyclooxygenase, fenbufen is effective in rheumatoid arthritis and osteoarthritis. ${ }^{17)}$ Although NSAIDs such as diclofenac may inhibit tumor growth in vitro $\left(\mathrm{IC}_{50}: 360 \mu \mathrm{M}\right)^{18)}$ and in vivo ${ }^{19)}$ there was no significant improvement in cytotoxicity through modification of other NSAIDs, for instance fenoprofen. ${ }^{20)}$ Therefore, fenbufen (D18) is an interesting probe for studying the relationship between these two diseases through structural modification. Furthermore, C18 is a potential hit and may act as a starter for further screening of a new hit compound or even a lead compound. The potential enzyme 


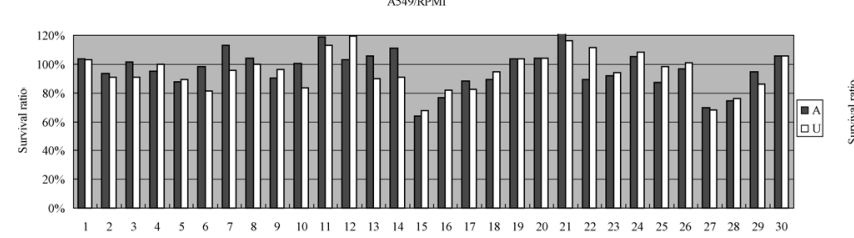

(a)

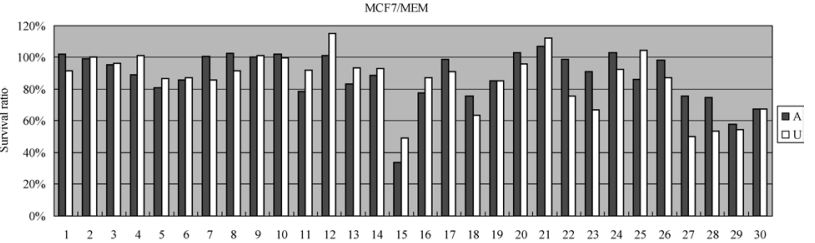

(b)

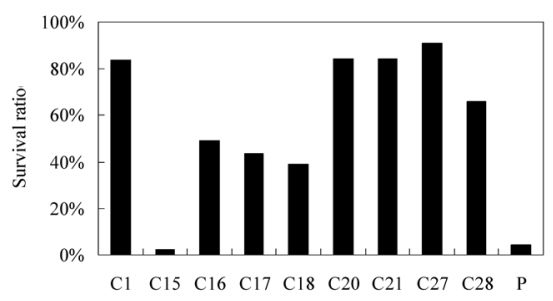

(c)

Fig. 3. (a) Assay of Cytotoxicity against A549 Cell Line by the Libraries Prepared from Uridine Analogue 1 and Arabinosyl Uridine Analogue 2, (b) Assay of Cytotoxicity against MCF-7 Cell Line by the Libraries Prepared from Uridine Analogue 1 and Arabinosyl Uridine Analogue $\mathbf{2}$ and (c) Assay of Cytotoxicity against MCF-7 Cell Lines by the Libraries Prepared from $n$-Butanamine (P: Cisplatin)

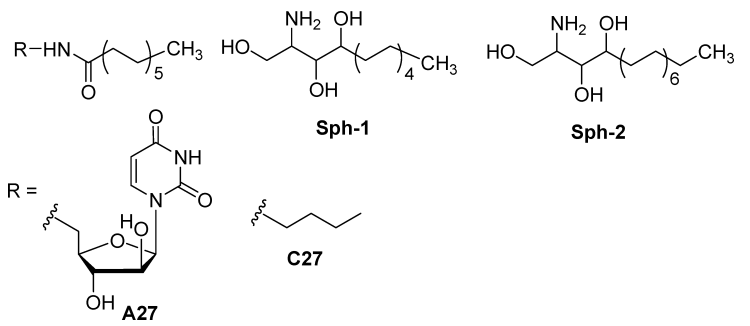

Fig. 4. Lipid-Containing Compounds Used in the Bioassay

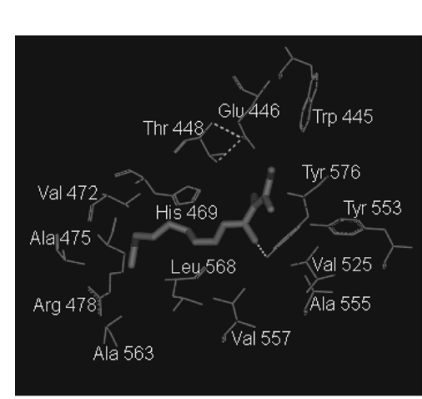

(a)

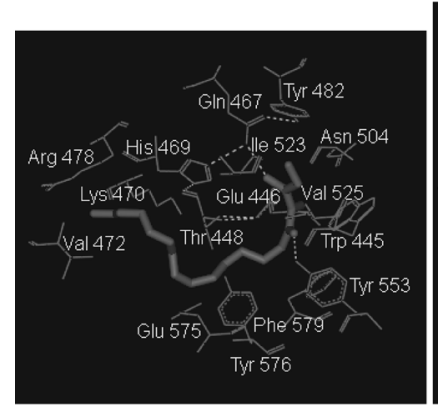

(c)

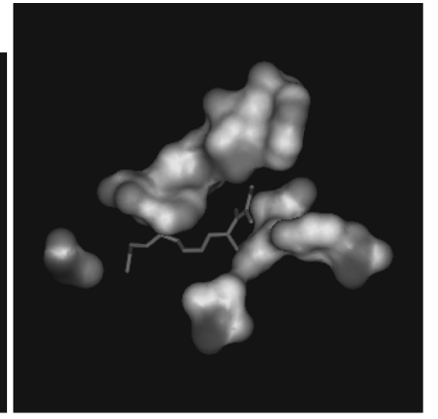

(b)

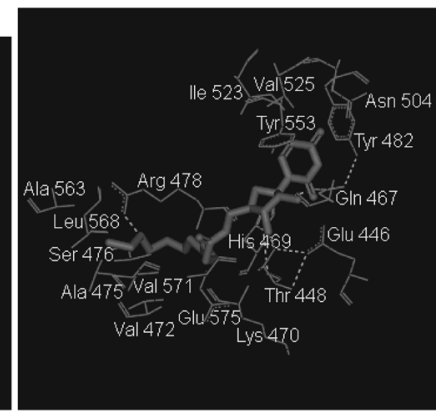

(d)
Fig. 5. (a) Docking of SPh-1 to the Active Site Defined by the Ligand of Ceramide, (b) Schematic Representation of the Electronic Clouds of Amino Acid Residues Participating in the Binding to Sph-1, (c) Amino Acid Residues Participating in the Binding to Sph-2 and (d) Amino Acid Residues Participating in the Binding to $\mathbf{U 2 7}$ targeted by $\mathbf{C 1 8}$ has been suggested to be cyclooxygenase $(\mathrm{COX}){ }^{21)} \mathrm{COX}-2$ is an inducible cyclooxygenase isoform that plays a major role in inflammation and has been found to be hyperexpressed in several human tumors. ${ }^{22-24)} \mathrm{COX}-2$ overexpression is involved in cancer growth and invasion. ${ }^{25}$ ) Various NSAIDS have been studied as anticancer drugs. Since the bioactive flurbiprofen mimics our butylfenbufen, the 3-D crystal structure of the complex formed by prostaglandin $\mathrm{H} 2$ synthase-1 from goat with flurbiprofen was chosen as model (Fig. 6a). When examining the inner structure formed by flurbiprofen within the active site, butyl fenbufen-rather than fenbufen-shared a similar environment (Figs. 6b, c). This is likely to be ascribed to the hydrogen bond formed between the oxo group and the terminal amino group of arginine-120 and the van der Waals contact formed between butyl group and Val 116 as well as Leu93.

Instead of a hydrogen bond formed between the oxo group and arginine-120 as for butyl fenbufen, fenbufen formed a hydrogen bond between the oxo group and tyrosine-355. The slightly incline-to-the-left structure weakened the nonpolar contact of the biphenyl ring with the deep pocket of active site, thereby diminishing its activity. Nevertheless, in spite of the success in the elucidation of the structure-activity relationship through molecular-docking, the apoptotic mechanism in terms of the block of COX-2 might not fully account for the subtle cytotoxicity of butylfenbufen. Accordingly, targeting cyclooxygenase may be not the sole antiproliferative mechanism of NSAIDs. ${ }^{22)}$ We therefore examined the protein data bank (PDB) to find the related report regarding the probable human-derived enzyme responsible for the proapoptotic activity. The screening results obtained by confining to the substructure of diphenyl rings indicated that proteins of the Bcl-x or Bcl-2 families overexpressed in many cancers fit these criteria. ${ }^{26)}$ However, a contradictory docking result for butylfenbufen was obtained (Fig. 7a). In contrast to the report of the extension of the biphenyl ring of 4 '-fluoro-1,1'-biphenyl-4-carboxylic acid (4-FC) into the deep pocket of the active site (Fig. 7b), an inverted binding of the butylfenbufen was evident. Furthermore, most of the binding energy of this model is resulting from the coverage 
Table 2. $\mathrm{IC}_{50}$ of the Compounds Purified from Independent Synthesis

\begin{tabular}{|c|c|c|c|c|c|c|c|c|c|c|c|c|c|c|c|c|}
\hline Samples & & C18 & U18 & D18 & C15 & A15 & D15 & U27 & Sph-1 & Sph-2 & A16 & $\mathrm{C} 16$ & X16 & D16 & U1 & Cisplatin \\
\hline Cell lines & A549 & 100 & $>100$ & $>100$ & 18 & $>100$ & $84 \pm 16$ & $>100$ & 50 & 38 & $>100$ & $>100$ & $>100$ & $>100$ & $>100$ & $8 \pm 3$ \\
\hline$(\mu \mathrm{M})$ & MCF 7 & 87 & $>100$ & $>100$ & $8 \pm 5$ & $>100$ & $26 \pm 2$ & ca. 100 & 40 & 20 & $>100$ & $>100$ & $>100$ & $>100$ & $>100$ & $25 \pm 6$ \\
\hline
\end{tabular}

Data are the mean of two or three experiments and are reported as the mean [standard error of the mean (S.E.M.)].

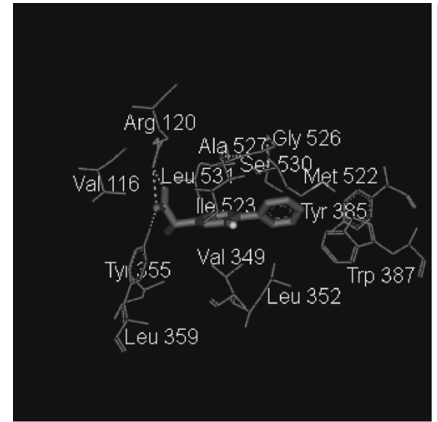

(a)

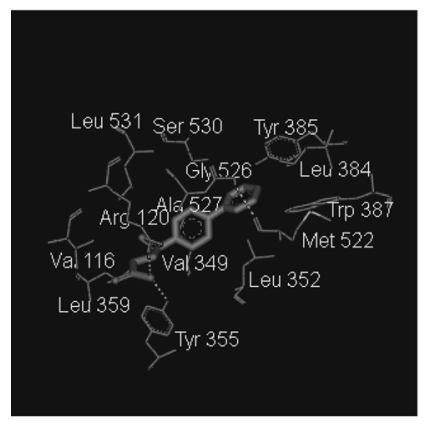

(c)

Fig. 6. (a) The Amino Acid Residues of 1 CQE Participating in Direct Binding to Flurbiprofen, (b) The Amino Acid Residues of 1 CQE Participating in Direct Binding to Butyl Fenbufen and (c) The Amino Acid Residues of 1 CQE Participating in Direct Binding to Fenbufen

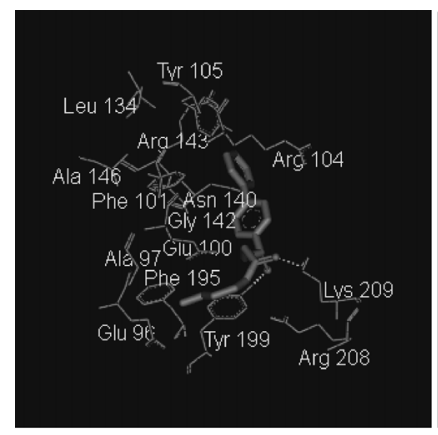

(a)

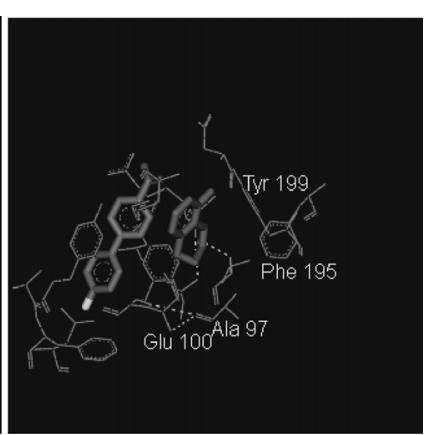

(b)
Fig. 7. (a) Residues of Active Site of Bcl-x Responsible for the Binding to Butylfenbufen and (b) Binding of 4-FC and TN1 to 1YSG (Bcl-x)

Biphenyl ring extending into the active site.

of the biphenyl group on the protein surface, a result that is not consistent with 4-FC's. The proapoptotic activity of butylfenbufen is thus unlikely to occur via inhibition of Bcl$\mathrm{x}$ proteins.

Acid moieties D15, known as ethacrynic acid, are classified as a group of diuretics that can block $\mathrm{Na}^{+}-\mathrm{K}^{+}-2 \mathrm{Cl}^{-}$ symporter in the thick ascending limb of the loop of Henle. They are generally used in patients with acute pulmonary

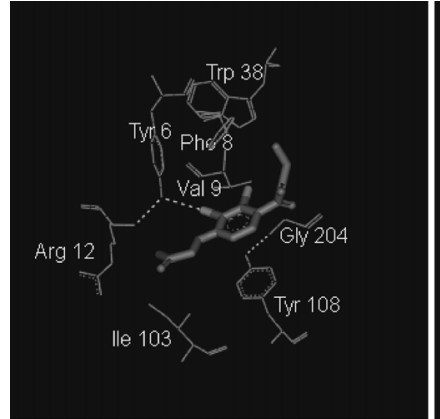

(a)

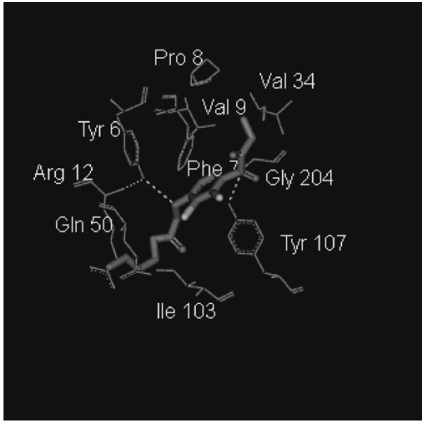

(b)
Fig. 8. (a) 2gss Docking with Ethacrynic Acid and (b) 2gss Docking with Butyl Ethacrynic Amide C15

edema. ${ }^{17)}$ Furthermore, D15 is an inhibitor of betaglutathiontransferase (BGTT) whose upregulation has been associated with drug resistance during chemotherapy of various cancers. $^{27,28)}$ Further analysis of the binding pattern between C15 and BGTT was performed by using the DS program according to $3 \mathrm{D}$-data of $2 \mathrm{gss}$ from the PDB bank (Fig. 8a). ${ }^{29)}$ Compared to ethacrynic acid, the extra butyl group extends into the deep pocket, an unidentified extra site freely available for extra stabilization (Fig. 8b). Furthermore, both residues of tyrosine-107 and phenyl alanine- 7 near the entrance of the pocket provided a primary stabilization for the benzene ring of $\mathbf{C 1 5}$ through a pi-pi stackering, a mimic of a sandwich complex. The terminal amido group in the glutamine-51 residue may provide indirect polar contact with the amido group of butyl ethacrynic amide. Interestingly, despite the presence of the butyl group, there is a loose space surrounded by the residues of glutamine-64, serine-65 (not specified in Fig. 8b) and the terminal butyl group of butyl ethacrynic amide. This may provide a base for future modifications of the butyl group in order to develop potential inhibitors.

Interestingly, a recent study has shown that a butyl ester derivative of ethacrynic acid may induce apoptosis in leukemia cells. ${ }^{30)}$ Our approach may thus provide a new avenue to explore new potential compounds based on the concept of "old drug new use."

In conclusion, we have described a simple method for screening an in vitro solution-derived library using the MTT assay at the cellular level. The probe screening of this minilibrary (comprising of 69 compounds derived from three core amines) was helpful in the quest of novel hit compounds such as C18. It also shows enough sensitivity to detect bioactive compounds based on a relative survival ratio of $>60 \%$ for controls. The hit compound $\mathbf{C 1 5}$ may be further modified as a potential hit compound through a series of high throughput screening (HTS). Investigation of the mechanism responsible for the inhibition of proliferation of cancer cells was performed by molecular docking using the DS program. The 
cytotoxicity of U27, C18 and $\mathbf{C 1 5}$ discovered through the combinatorial approach is likely to occur mainly via bindingmediated inhibition of apoptosis-regulating enzymes.

\section{Experimental}

The reagents used in the amide bond formation was core amine $(1 \mathrm{mg}$, $4 \mu \mathrm{mol})$, carboxylic acid (1 eq), diisopropyl ethyl amine (DIEA) (1.2 eq) and 2-(1H-benzotriazol-1-yl)-1,1,3,3-tetramethyluronium hexafluorophosphate (HBTU) (1.1 eq). Both the starting core amine and the carboxylic acids were prepared as a stock solution of DMSO at a concentration of $0.1 \mathrm{mmol} / 200 \mu \mathrm{l}$ and $5 \mu \mathrm{mol} / 10 \mu \mathrm{l}$, respectively. HBTU and DIEA were dissolved in DMSO as a concentration of $5 \mu \mathrm{mol} / 10 \mu \mathrm{l}$, respectively. Each of the acid portion was firstly mixed with HBTU in a plastic tube for $30 \mathrm{~s}$, followed by the addition of a mixture of core amine $(10 \mu \mathrm{l})$ and DIEA $(10 \mu \mathrm{l})$ in a total volume of $40 \mu \mathrm{l}$. All vials were shaked for $1 \mathrm{~min}$. A portion of the mixture $(10 \mu \mathrm{l})$ was transferred to a novel tube followed by addition of $990 \mu \mathrm{l}$ of water. A volume of $10 \mu \mathrm{l}$ was pipetted out and added into the corresponding well of microtiterplate planted with $100 \mu \mathrm{l}$ of A549 or MCF7 cells in a concentration of $30000 \mathrm{cells} / \mathrm{ml}$. After an incubation of $2 \mathrm{~d}$, the supernatants were removed through washing followed by MTT reagents and the absorbance at $580 \mathrm{~nm}$ was recorded according to the usual protocol conducted routinely in the medicinal chemistry laboratory.

Acknowledgment We are grateful to the National Science Council of Taiwan and CGMH_NTHU Joint Research for providing financial support (NSC-95-2113-M-007-039 and CGTH96N2342E1).

Supporting Information Available Details of the experimental procedures including bioassay, characterization data and molecular docking for library members including ${ }^{1} \mathrm{H}$ - and ${ }^{13} \mathrm{C}-\mathrm{NMR}$ and molecular docking by DS program under ligandfit working model for library members.

\section{References}

1) Brik A., Wu C.-Y., Wong C.-H., Org. Biomol. Chem., 4, 1446-1457 (2006).

2) Best M., Brik A., Chapman E., Lee L., Cheng W.-C., Wong C.-H., ChemBioChem, 5, 811-819 (2004).

3) Wu C.-Y., Chang, C.-F., Chen J. S. Y., Lee, S.-T., Wong C.-H., Lin, C.H., Angew. Chem.-Int. Edit., 42, 4661-4664 (2003).

4) Lee L. V., Mitchell M. L., Huang S. J., Fokin V. V., Sharpless K. B., Wong C. H., J. Am. Chem. Soc., 125, 9588-9589 (2003).

5) Brik A., Lin Y.-C., Elder J. Wong C.-H., Chem. Biol., 9, 891-896 (2002).

6) Lee S. G., Chmielewski J., Chem. Biol., 13, 421-426 (2006).

7) Yu C.-S., Chiang L.-W., Wu C.-H., Wang R.-T., Chen S.-W., Wang H.Y., Yeh C.-H., Nucl. Med. Biol., 33, 367-370 (2006).

8) Yu C.-S., Wu C.-H., Chiang L.-W., Pei K., Hsu Z.-K., Synthesis, 2006 , 3835-3840 (2006).

9) Yu C.-S., Wang R.-T., Chiang L.-W., Lee M.-S., Tetrahedron Lett., 48, 2979-2982 (2007).
10) Winans K. A., Bertozzi C. R., Chem. Biol., 9, 113-129 (2002).

11) Teixeira-Clerc F., Julien B., Grenard P., Van Nhieu J. T., Deveaux V., Li L. Y., Serriere-Lanneau V., Ledent C., Mallat A., Lotersztajn S., Nat. Med., 12, 671-676 (2006).

12) Ogretmen B., Hannun Y. A., Nat. Rev. Cancer, 4, 604-616 (2004).

13) Coursol S., Fan L. M., Le Stunff H., Spiegel S., Gilroy S., Assmann S. M., Nature (London), 423, 651-654 (2003).

14) Padrón J. M., Curr. Med. Chem., 13, 755-770 (2006).

15) Olayioye M. A., Vehring S., Müller P., Hermann A., Schiller J., Thiele C., Lindeman G. J., Visvader J. E., Pomorski T., J. Biol. Chem., 280 , 27436-27442 (2005).

16) Kudo N., Kumaga K., Tomishige N., Yamaji T., Wakatsuki S., Nishijima M., Hanada K., Kato R., Proc. Natl. Acad. Sci. U.S.A., 105, 488 - 493 (2008).

17) Hardman J. G., Goodman G. A., Limbird L. E., "Goodman and Gilman's The Pharmacological Basis of Therapeutics," 9th ed., McGraw-Hill Companies, Southern California, 1996.

18) Johnsen J. I., Lindskog M., Ponthan F., Pettersen I., Elfman L., Orrego A., Sveinbjornsson B., Kogner P., Cancer Res., 64, 7210-7215 (2004).

19) Takada Y., Bhardwaj A., Potdar P., Aggarwal B. B., Oncogene, 23, 9247-9258 (2004).

20) Barbarić M., Kralj M., Marjanović M., Husnjak I., Pavelić K., Filipovic-Grcić J., Zorc D., Zorc B., Eur. J. Med. Chem., 42, 20-29 (2007).

21) Thun M. J., Henley S. J., Patrono C., J. Natl. Cancer Inst., 94, 252266 (2002).

22) Bock J. M., Menon S. G., Goswami P. C., Sinclair L. L., Bedford N. S., Domann F. E., Trask D. K., Mol. Carcinog., 46, 857-864 (2007).

23) Brown J. R., DuBois R. N., Clin. Cancer Res., 10, 4266s-4269s (2004).

24) Lee D. W., Sung M. W., Park S. W., Seong W. J., Roh J. L., Park B., Heo D. S., Kim K. H., Anticancer Res., 22, 2089-2096 (2002).

25) Bottone F. G., Moon Y., Kim J. S., Alson-Mills B., Ishibashi M., Eling T. E., Mol. Cancer Ther. 4, 693-703 (2005).

26) Oltersdorf T., Elmore S. W., Shoemaker A. R., Armstrong R. C., Augeri D. J., Belli B. A., Bruncko M., Deckwerth T. L., Dinges J., Hajduk P. J., Joseph M. K., Kitada S., Korsmeyer S. J., Kunzer A. R., Letai A., Li C., Mitten M. J., Nettesheim D. G., Ng S., Nimmer P. M., O'Connor J. M., Oleksijew A., Petros A. M., Reed J. C., Shen W., Tahir S. K., Thompson C. B., Tomaselli K. J., Wang B. L., Wendt M. D., Zhang H. C., Fesik S. W., Rosenberg S. H., Nature (London), 435, $677-681$ (2005)

27) Townsend D. M., Tew K. D., Oncogene, 22, 7369-7375 (2003).

28) Zhang K., Mack P., Wong K. P., Int. J. Oncol., 12, 871-882 (1998).

29) Oakley A. J., Rossjohn J., Lo Bello M., Caccuri A. M., Federici G., Parker M. W., Biochemistry, 36, 576-585 (1997).

30) Wang K., Li C., Song D., Zhao G., Zhao L., Jing Y., Cancer Res., 67, 7856-7864 (2007). 